\title{
Nasal Absorption and Pharmacokinetic Disposition of Salmon Calcitonin Modified with Low Molecular Weight Polyethylene Glycol
}

\author{
Beom Soo Shin, Ji Hoon Jung, Kang Choon Lee, and Sun Dong Yoo* \\ College of Pharmacy, Sungkyunkwan University; 300 Chonchon-dong, Changan-gu, Suwon, Kyonggi-do, 440-746, Korea. \\ Received March 2, 2004; accepted May 27, 2004
}

This study was performed to examine the absorption potential of polyethylene glycol (PEG)-modified salmon calcitonin (sCT) in rats administered via the nasal route. Previous studies have used relatively high molecular weight polyethylene glycols (e.g., $\geq 5000$ daltons) for PEG-modification of sCT to provide increased metabolic stability and biological half-life. Unlike these studies, the present study utilized a low molecular weight succinimidyl-propionated monomethoxy-poly(ethylene glycol) (MW 2000). It was hypothesized that the potential for membrane transport would not be significantly altered due to a relatively small increase in the molecular size while the metabolic stability would be enhanced due to resistance to proteolytic degradation. After PEG-modification of sCT, the mono-PEG positional isomer (mono-PEG ${ }_{2 \mathrm{k}}-\mathrm{sCT}$ ) was separated from di-PEG ${ }_{2 \mathrm{k}}$-sCT, tri$\mathrm{PEG}_{2 \mathrm{k}}$-sCT, and unmodified $\mathrm{sCT}$ by size exclusion chromatography. The mono-PEG ${ }_{2 \mathrm{k}}-\mathrm{sCT}$ and unmodified $\mathrm{sCT}$ were radioiodinated, and the resulting ${ }^{125} \mathrm{I}-\mathrm{sCT}$ and ${ }^{125} \mathrm{I}-\mathrm{mono}-\mathrm{PEG}_{2 \mathrm{k}}-\mathrm{sCT}$ were separated from free iodine by $\mathrm{RP}$ HPLC and confirmed by MALDI-TOF MS. The ${ }^{125} \mathrm{I}-\mathrm{sCT}$ and ${ }^{125} \mathrm{I}-\mathrm{mono}-\mathrm{PEG}_{2 \mathrm{k}}$-sCT were administered to rats via the nasal route, and serial blood, tissue, and urine samples were taken for up to $36 \mathrm{~h}$ for the determination of radioactivity. Mono- $\mathrm{PEG}_{2 \mathrm{k}}$-sCT exhibited significantly increased AUC $(20638 \mathrm{vs} .3650 \mathrm{ng} \cdot \mathrm{min} / \mathrm{ml}), t_{\max }(520 v s$. $77 \mathrm{~min})$, and $t_{1 / 2, \lambda \mathrm{z}}(923 \mathrm{vs} .199 \mathrm{~min})$ compared with unmodified $\mathrm{sCT}$. This study demonstrates that mono-PEG $\mathbf{P}_{2 \mathrm{k}}{ }^{-}$ sCT is absorbed systemically when given by the intranasal route, exhibiting altered absorption kinetics compared with unmodified SCT.

Key words salmon calcitonin ( $\mathrm{sCT})$; PEGylation; pharmacokinetics; nasal absorption

Salmon calcitonin $(\mathrm{sCT})$ is a therapeutic polypeptide hormone consisting of 32 amino acids (3432 daltons). It is currently marketed either as a solution for intramuscular or subcutaneous injection, or as a nasal spray in the treatment of postmenopausal osteoporosis, symptomatic Paget's disease of the bone, and hypercalcemia due to malignancy. Like other peptide therapeutics, $\mathrm{SCT}$ is easily degraded by proteolytic enzymes and exhibits a short elimination half-life and low bioavailability in humans. ${ }^{1-3)}$ The absolute bioavailability of $\mathrm{sCT}$ after subcutaneous injection has been reported as $11.2-23.1 \%$ in rats. ${ }^{4,5)}$ Administration of $\mathrm{sCT}$ via the nasal route results in a low bioavailability but is shown to be effective, decreasing the osteoclastic bone resorption in humans. ${ }^{6-8)}$ The presence of tryptic endopeptidase activities appears to be crucial for $\mathrm{SCT}$ cleavage in the nasal mucosa. ${ }^{9,10)}$

We previously reported a chemical modification of $\mathrm{SCT}$ by covalent linkage with polyethylene glycol (PEG) ${ }^{11-13)}$ PEG may bind to $\mathrm{SCT}$ at lysine 11 , lysine 18 , and N-terminus (cysteine 1) positions, yielding mono-, di-, and tri-PEGylated sCTs depending on the number of attached PEG molecules per molecule of sCT. Therefore, PEG modification results in a heterogeneous mixture of mono-, di-, and tri-PEG-sCTs. Formation of mono-PEG-sCT appears to be favored over that of di-PEG-sCT, while the formation of tri-PEG-sCT is minimal. Mono- and di-PEGylated sCTs exhibit substantially improved stability in rat liver and kidney homogenates over unmodified $\mathrm{sCT}^{11)}$ while retaining the biological activity similar to that of unmodified $\mathrm{sCT}$ as examined by the adenosine cyclic $3^{\prime}, 5^{\prime}$-phosphate (cAMP) assay. ${ }^{12)}$

Unlike other previous studies ${ }^{11-14)}$ utilizing high molecular weight PEGs (MW 5000 and 12000) for chemical modification, this study used a lower molecular size succinimidylpropionated monomethoxy-propylene glycol (SP-mPEG,
MW 2000). The nasal absorption of synthesized mono$\mathrm{PEG}_{2 \mathrm{k}}$-SCT was further examined in rats compared with that of unmodified SCT. The chemical modification of sCT with low MW PEG was anticipated to increase the nasal absorption due to improved metabolic stability in the nasal mucosa. Our findings showed that the nasal absorption kinetics of mono- $\mathrm{PEG}_{2 \mathrm{~K}}-\mathrm{SCT}$ was altered, exhibiting increased $A U C$, $C_{\max }, t_{\max }$, and $t_{1 / 2}$ as compared with those of unmodified $\mathrm{sCT}$.

\section{Experimental}

Chemicals Salmon calcitonin (synthetic cyclic sCT) and $\mathrm{Na}^{125} \mathrm{I}$ were purchased from BACHEM (Torrance, CA, U.S.A.) and NEN (Boston, MA, U.S.A.), respectively. Succinimidyl-propionated monomethoxy-poly(ethylene glycol) (SP-mPEG, MW 2000) was purchased from Shearwater Polymers (Huntsville, AL, U.S.A). IODO-GEN was purchased from PIERCE (Rockford, IL, U.S.A.), and ketamine and xylazine from Sigma (St. Louis, MO, U.S.A). Acetonitrile and trifluoroacetic acid (HPLC grades) were purchased from J.T. Baker (Phillipsberg, NJ, U.S.A.) and Acros Organics (Springfield, NJ, U.S.A.), respectively. Other chemicals used in the study were of analytical grade.

Preparation and Purification of SP-mPEG-Modified sCT SP-mPEG (MW 2000) $(1 \mathrm{mg}$ ) was added to $0.2 \mathrm{ml}$ of sCT solution $(5 \mathrm{mg} / \mathrm{ml}$ in $10 \mathrm{~mm}$ phosphate buffer, $\mathrm{pH}$ 7.5). The mixture was shaken gently at room temperature for $25 \mathrm{~min}$ and the reaction was stopped by the addition of an excess amount of $1.0 \mathrm{~m}$ glycine solution. The reaction mixture was subjected to size exclusion chromatography on a Superose 12 HR 10/30 column (AmershamPharmacia, Uppsala, Sweden) eluted with $10 \mathrm{~mm}$ phosphate buffer ( $\mathrm{pH} 7.4)$ at a flow rate of $0.4 \mathrm{ml} / \mathrm{min}$. In fluorescence measurements, excitation and emission wavelengths were set at 280 and $315 \mathrm{~nm}$, respectively (Hitachi F4010 Spectrofluorometer, Tokyo, Japan). Fractions corresponding to mono$\mathrm{PEG}_{2 \mathrm{~K}}-\mathrm{sCT}$ were collected, concentrated to $1.5 \mathrm{mg} / \mathrm{ml}$ using Centricon- 10 concentrators (Amicon, Beverly, MA, U.S.A.), and kept at $4{ }^{\circ} \mathrm{C}$ until use.

Radioiodination of sCT and PEG-Modified sCT A portion $(0.2 \mathrm{mg})$ of IODO-GEN was dissolved in $0.2 \mathrm{ml}$ of chloroform in an Eppendorf tube and was thoroughly dried under a stream of nitrogen gas at room temperature. To this tube were added $1 \mathrm{mCi}$ of $\mathrm{Na}^{125} \mathrm{I}, 0.2 \mathrm{ml}$ of $\mathrm{SCT}$ and mono$\mathrm{PEG}_{2 \mathrm{~K}}$-SCT $(1.5 \mathrm{mg} / \mathrm{ml}$ in $10 \mathrm{~mm}$ phosphate buffer, $\mathrm{pH}$ 7.4). After reaction for $5 \mathrm{~min}$, radioiodinated species and free iodine were separated by reverse- 
phase HPLC with a flow-through radioisotope detector, and the samples collected were lyophilized. The radioactivity of these samples was measured by gamma counting (Cobra ${ }^{\mathrm{TM}}$ Series Auto-Gamma Counting System, Packard Instrument, Groningen, Netherlands).

MALDI-TOF Mass Spectrometry ${ }^{125} \mathrm{I}-\mathrm{sCT}$ and ${ }^{125} \mathrm{I}_{-\mathrm{mono}}-\mathrm{PEG}_{2 \mathrm{~K}}-\mathrm{sCT}$ were characterized and confirmed by MALDI-TOF mass spectrometry (Voyager, PerSeptive Biosystems, Cambridge, MA, U.S.A.). The analysis was performed in a linear mode, and data for 2-ns pulses of the $337 \mathrm{~nm}$ nitrogen laser were averaged for each spectrum. The linear, positive-ion TOF detection was conducted using an acceleration potential of $20 \mathrm{kV}$. Spectra were obtained by summing $>128$ laser shots and smoothened with a 19-point Savitzky-Golay filter. The external calibration was performed using a mixture of angiotensin I, ACTH (clip 1-17), ACTH (clip 18-39), ACTH (clip 7-38), and bovine insulin. The matrix used for the analysis of sCT and mono-PEG ${ }_{2 \mathrm{k}}$-sCT was $\alpha$-cyano-4-hydroxycinnamic acid in $50 \%$ acetonitrile containing $0.1 \%$ TFA at a ratio of $1: 2$. The solution was thoroughly mixed on a vortex mixer, and $1 \mu \mathrm{l}$ was deposited onto the sample plate and dried by rapid vacuum evaporation.

HPLC Conditions for Radioiodinated sCT and PEGylated sCT The HPLC system was consisted of two Waters pumps (Model 510), 6-port switching valve, and Ramona 2000 flow-through radioisotope detector (Raytest, Straubenhardt, Germany). The analytical column was LiChrospher $100 \mathrm{RP}-18$ cartridge $(4.0 \times 125 \mathrm{~mm}, 5 \mu \mathrm{m})$ with a guard column $(4.0 \times 4 \mathrm{~mm}$, $5 \mu \mathrm{m})$ (Merck, Darmstadt, Germany). A linear gradient elution was carried out at a flow rate of $1 \mathrm{ml} / \mathrm{min}$ at a solvent $\mathrm{A}(0.1 \%$ trifluoroacetic acid in distilled water): solvent $\mathrm{B}(0.1 \%$ trifluoroacetic acid in acetonitrile) ratio of $80: 20 \%$ to $20: 80 \%$ over $10 \mathrm{~min}$. Additional elution was allowed for $10 \mathrm{~min}$ with $20 \%$ B between injections. The radioactivity of the effluents was determined using a flow-through radioactive detector.

Animals Male Sprague Dawley rats (7 weeks of age, 190-200 g) were obtained from Hanlim Co. (Suwon, Korea). The rats were kept in plastic rat cages and housed in an animal facility (temperature $23 \pm 2{ }^{\circ} \mathrm{C}$ ) with a light/dark cycle of $12 / 12 \mathrm{~h}$ and a relative humidity of $50 \pm 10 \%$. The animals were fed a standard rat diet (Daejong Co., Seoul, Korea) and had free access to water.

Nasal Administration Study Rats were anesthetized by i.m. injection of ketamine and xylazine $(90 / 10 \mathrm{mg} / \mathrm{kg})$, and were cannulated with PE tubing $(0.58 \mathrm{~mm}$ i.d. and $0.96 \mathrm{~mm}$ o.d., Natsume Co., Tokyo, Japan) in the right jugular vein. ${ }^{125} \mathrm{I}-\mathrm{sCT}$ or ${ }^{125} \mathrm{I}-\mathrm{mono}-\mathrm{PEG}_{2 \mathrm{~K}}-\mathrm{SCT}$ was dissolved in $100 \mathrm{~mm}$ phosphate buffered saline ( $\mathrm{pH} 7.4)(20 \mu \mathrm{g}$ in $10 \mu \mathrm{l})$. After at least one day of recovery, the rats were administered ${ }^{125} \mathrm{I}-\mathrm{sCT}$ or ${ }^{125} \mathrm{I}-\mathrm{mono}_{-} \mathrm{PEG}_{2 \mathrm{~K}}-\mathrm{SCT}$ via the nasal route (volume $10 \mu \mathrm{l})$ under ketamine and xylazine $(90 / 10 \mathrm{mg} / \mathrm{kg}$ ) anesthesia ( $n=9$ each). A micro-syringe (Hamilton Co., Reno, Nevada) with a silastic tubing $(0.64 \times 1.19 \mathrm{~mm}$ Dow Corning, Midland, U.S.A) attached to the needle was used in the study. After nasal administration, the animals were kept in metabolic cages during the dosing and sampling period. The average specific radioactivity of administered ${ }^{125} \mathrm{I}-\mathrm{sCT}$ and ${ }^{125} \mathrm{I}-\mathrm{mono}-$ $\mathrm{PEG}_{2 \mathrm{~K}}$-sCT was approximately $70000000-150000000 \mathrm{cpm}$. Serial blood samples (approximately $0.3 \mathrm{ml}$ each) were withdrawn from the jugular vein at $0,10,30 \mathrm{~min}$ and at 1, 1.5, 3, 6, 9, 12, 24 and $36 \mathrm{~h}$ into Eppendorf tubes placed in an ice bath. Equal volumes of isotonic saline were replaced after each sampling. Serum samples were harvested immediately by centrifugation at $10000 \mathrm{rpm}$ for $10 \mathrm{~min}$. A portion $(200 \mu \mathrm{l})$ of $20 \%$ trichloroacetic acid (TCA) solution was added to $100 \mu$ of serum samples. The mixture was mixed on a vortex mixer for $10 \mathrm{~s}$ and centrifuged at $10000 \mathrm{rpm}$ for $10 \mathrm{~min}$. The radioactivity of resulting supernatants and precipitates was measured by gamma counting. Urine samples were also collected over the $36 \mathrm{~h}$ period in metabolic cages. A portion $(200 \mu \mathrm{l})$ of the $20 \%$ TCA solution was added to the urine samples, mixed on a vortex mixer, and centrifuged at $10000 \mathrm{rpm}$ for $10 \mathrm{~min}$, and the radioactivity of the resulting supernatants and precipitates was measured by gamma counting. In a separate study, tissue distribution characteristics of ${ }^{125} \mathrm{I}-\mathrm{sCT}$ and ${ }^{125} \mathrm{I}-$-mono- $^{-} \mathrm{PEG}_{2 \mathrm{~K}}-\mathrm{sCT}$ were determined in rats after nasal administration ( $n=9$ each). ${ }^{125} \mathrm{I}-\mathrm{sCT}$ and ${ }^{125} \mathrm{I}-\mathrm{mono}_{-} \mathrm{PEG}_{2 \mathrm{~K}}{ }^{-}$ $\mathrm{SCT}$ were given in the same manner described above, sacrificed $12 \mathrm{~h}$ after dosing, and the liver, kidney, thyroid, spleen, heart, lungs and muscle were excised, blot dried and weighed. The total radioactivity was determined for these tissue samples by gamma counting.

Data Analysis Serum concentrations of sCT and mono-PEG-sCT vs. time data were analyzed by a noncompartmental method using the nonlinear least squared regression program WinNonlin (Scientific Consulting Inc., Cary, NC, U.S.A.). Pharmacokinetic parameter values were expressed as the mean \pm S.D. Statistical differences were tested by the unpaired Student $t$-test for the pharmacokinetic parameters between sCT and mono-PEG-sCT $(p<0.05)$.

\section{Results}

Figure 1 shows MALDI-TOF mass spectra of unmodified sCT and mono-PEG-sCT. In the mass spectrum, the molecular weight of sCT was found to be $3440.45 \mathrm{~m} / \mathrm{z}$ and the average molecular weight of mono- $\mathrm{PEG}_{2 \mathrm{k}}$-sCT was $5646.70 \mathrm{~m} / \mathrm{z}$. Average decay curves of the total radioactivity and the radioactivity corresponding to intact and degradation species after nasal administration of $\mathrm{SCT}$ and mono- $\mathrm{PEG}_{2 \mathrm{k}}-\mathrm{SCT}$ to rats $(n=9$ each) are shown in Fig. 2 . The average serum concentration-time profiles of unmodified $\mathrm{sCT}$ and mono$\mathrm{PEG}_{2 \mathrm{k}}-\mathrm{SCT}$ are shown in Fig. 3. The pharmacokinetic parameters of $\mathrm{sCT}$ and mono- $\mathrm{PEG}_{2 \mathrm{k}}$-sCT obtained after nasal administration are shown in Table 1. Mono- $\mathrm{PEG}_{2 \mathrm{k}}$-sCT exhibited a significantly increased time to reach the maximum concentration ( $520 \pm 167 \mathrm{vs}$. $77 \pm 22 \mathrm{~min})$, with no significant difference in the observed $C_{\max }(12.9 \pm 3.0 \quad v s$. $10.5 \pm 4.7 \mathrm{ng} / \mathrm{ml}$ ) as compared with unmodified sCT. The apparent terminal elimination half-life of mono- $\mathrm{PEG}_{2 \mathrm{k}}-\mathrm{sCT}$ was prolonged over unmodified $\mathrm{sCT} \quad(923 \pm 389$ vs. $199 \pm 97 \mathrm{~min})$. The $A U C$ was higher for mono- $\mathrm{PEG}_{2 \mathrm{k}}-\mathrm{sCT}$ than for unmodified sCT $(20638 \pm 9686$ vs. $3650 \pm 1894 \mu \mathrm{g} \cdot \mathrm{min} / \mathrm{l})$. The difference in $A U C$ remained statistically significant even when the dose-normalized values $(A U C / D) \quad$ were compared $\quad(0.18 \pm 0.09 \quad$ vs. $1.03 \pm 0.48 \mathrm{ng} \cdot \mathrm{min} / \mathrm{ml} / \mathrm{ng}$ ). The extent of urinary excretion of intact and degradation species of unmodified and mono-PEGylated sCTs after nasal administration is shown in Fig. 4. Mono- $\mathrm{PEG}_{2 \mathrm{k}}$-sCT and unmodified $\mathrm{sCTs}$ were excreted intact in urine in small quantities ( 0.03 vs. $0.02 \%$, respectively). The urinary excretion of degradation products was also low $(0.8-1.2 \%)$. The difference in the urinary excretion profiles between unmodified $\mathrm{sCT}$ and mono-PEG-sCT $\mathrm{S}_{2 \mathrm{k}}$ was not significant. The extent of total radioactivity $(\%)$ found in vari-
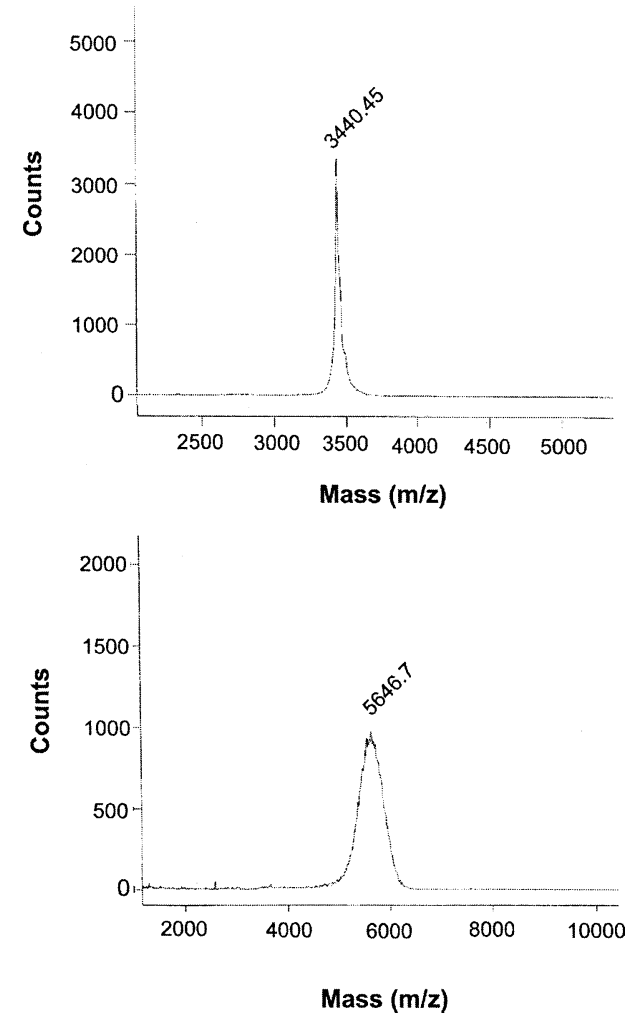

Fig. 1. MALDI-TOF Mass Spectra of Prepared ${ }^{125} \mathrm{I}-\mathrm{sCT}$ (Upper Panel) and ${ }^{125}$ I-mono- $\mathrm{PEG}_{2 \mathrm{k}}$-sCT (Lower Panel) 

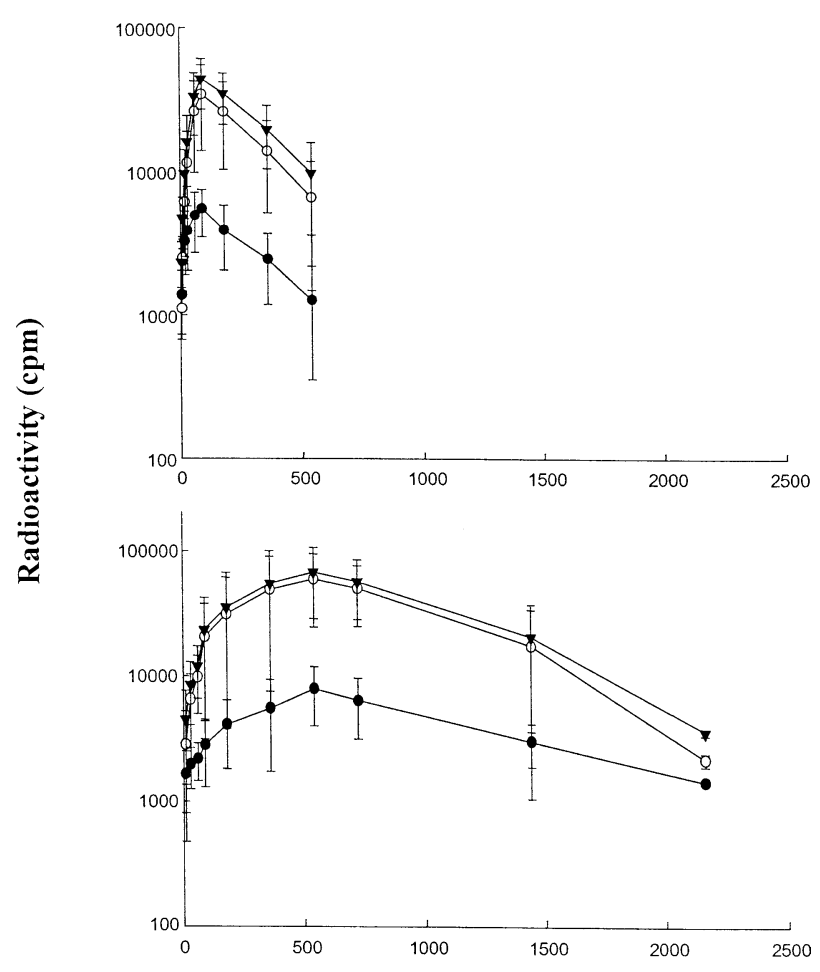

Time (min)

Fig. 2. Average Decay Curves of the Total Radioactivity $(\boldsymbol{\nabla})$ and the Radioactivities Corresponding to the Intact $(\bullet)$ and Degradation Species $(\bigcirc)$ Found in the Serum after Nasal Administration of sCT (Upper Panel) and Mono-PEG ${ }_{2 \mathrm{k}}$-sCT (Lower Panel) in Rats $(n=9$ Each)

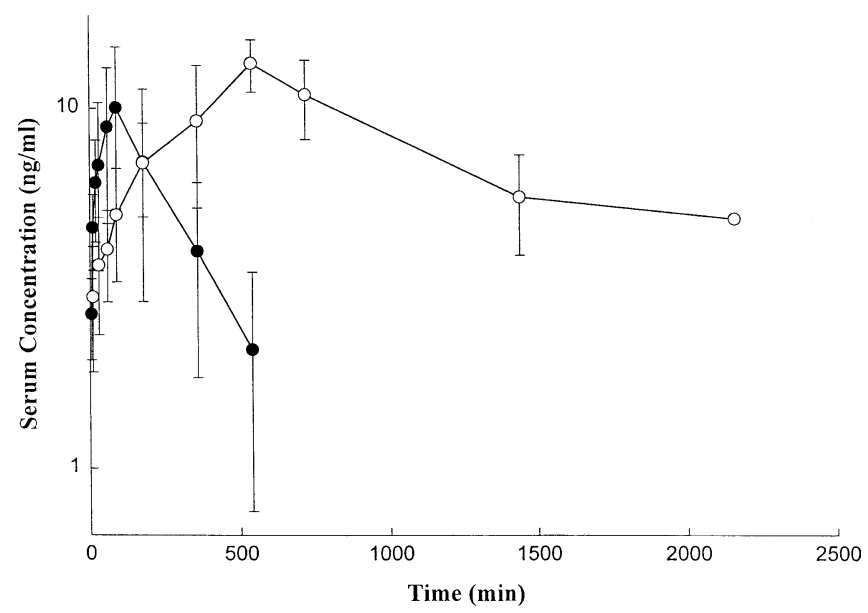

Fig. 3. Average Serum Concentration of Intact SCT vs. Time Curves Following Nasal Administration of Unmodified $\mathrm{SCT}(\bullet)$ and $\mathrm{Mono}_{-} \mathrm{PEG}_{2 \mathrm{~K}}-\mathrm{SCT}$ $(\bigcirc)$ in Rats $(n=9$ Each)

ous tissues $12 \mathrm{~h}$ after intranasal administration of $\mathrm{SCT}$ and mono- $\mathrm{PEG}_{2 \mathrm{k}}-\mathrm{SCT}$ is shown in Table 2. The highest radioactivity was found in the liver, followed by kidneys and lungs after nasal administration, and the levels in heart, thyroid, and spleen were low for both the unmodified and mono$\mathrm{PEG}_{2 \mathrm{k}}-\mathrm{sCT}$.

\section{Discussion}

To our knowledge, this study first examined the pharmacokinetics of PEG modified sCT via the nasal administration.

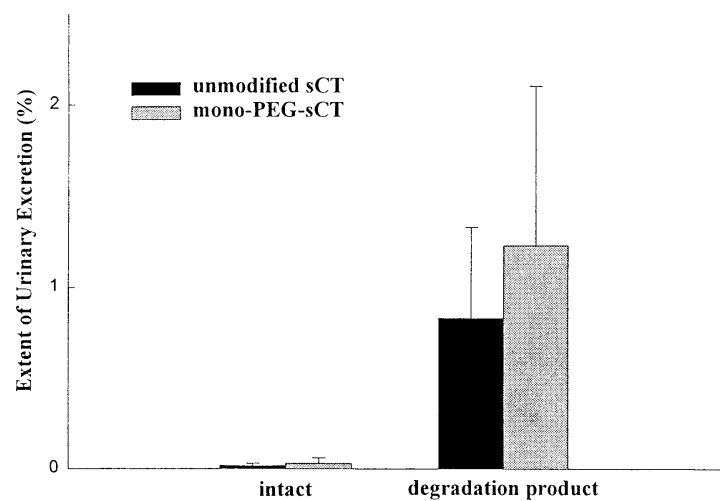

Fig. 4. Extent of Urinary Excretion (\%) of Intact $\mathrm{sCT}$ and Its Degradation Products in Rats after Nasal (Lower Panel) Administration of Unmodified sCT and Mono- $\mathrm{PEG}_{2 \mathrm{k}}$-sCT ( $\left.n=9 \mathrm{Each}\right)$

Table 1. Pharmacokinetic Parameters (Mean \pm S.D.) of Unmodified sCT and Mono- $\mathrm{PEG}_{2 \mathrm{k}}-\mathrm{SCT}$ Obtained after Nasal Administration to Rats $(n=9$ Each)

\begin{tabular}{lcc}
\hline \hline \multicolumn{1}{c}{ Parameter } & Unmodified sCT & Mono-PEG $_{2 \mathrm{k}}-\mathrm{sCT}$ \\
\hline$C_{\max }(\mathrm{ng} / \mathrm{ml})$ & $10.5 \pm 4.7$ & $12.9 \pm 3.0$ \\
$t_{\max }(\mathrm{min})$ & $77 \pm 22$ & $520 \pm 167^{a)}$ \\
$t_{1 / 2, \lambda \mathrm{z}}(\mathrm{min})$ & $199 \pm 97$ & $923 \pm 389^{a)}$ \\
$C l / F(\mathrm{ml} / \mathrm{min})$ & $7.4 \pm 5.2$ & $1.3 \pm 1.0^{a)}$ \\
$V_{\mathrm{ss}} / F(\mathrm{ml})$ & $1802 \pm 811$ & $1392 \pm 450$ \\
$A U C(\mathrm{ng} \cdot \mathrm{min} / \mathrm{ml})$ & $3650 \pm 1894$ & $20638 \pm 9686^{a)}$ \\
$A U C / D(\mathrm{ng} \cdot \mathrm{min} / \mathrm{ml} / \mathrm{ng})$ & $0.18 \pm 0.09$ & $1.03 \pm 0.48^{a)}$ \\
$M R T_{p . o .}(\mathrm{min})$ & $314 \pm 131$ & $1505 \pm 560^{a)}$ \\
\hline
\end{tabular}

a) Significantly different from unmodified $\mathrm{sCT}(p<0.05)$.

Table 2. The Extent of Total Radioactivity (Mean \pm S.D.) Found in Various Body Organs after Nasal Administration of Unmodified SCT and Mono$\mathrm{PEG}_{2 \mathrm{k}}$-sCT to Rats ( $n=9$ Each)

\begin{tabular}{lcc}
\hline \hline \multirow{2}{*}{ Tissue } & \multicolumn{2}{c}{ Radioactivity (\%) found in whole organ } \\
\cline { 2 - 3 } & Unmodified SCT & Mono- $^{a} \mathrm{PEG}_{2 \mathrm{k}}{ }^{-\mathrm{SCT}}$ \\
\hline Liver & $0.80 \pm 0.41$ & $1.03 \pm 0.65$ \\
Kidney & $0.30 \pm 0.14$ & $0.52 \pm 0.24$ \\
Lung & $0.18 \pm 0.12$ & $0.20 \pm 0.12$ \\
Heart & $0.06 \pm 0.03$ & $0.13 \pm 0.05^{b)}$ \\
Spleen & $0.04 \pm 0.02$ & $0.10 \pm 0.05$ \\
Thyroid & $0.04 \pm 0.03$ & $0.05 \pm 0.02$ \\
\hline
\end{tabular}

a) Determined $12 \mathrm{~h}$ after nasal administration. b) Significantly different from unmodified sCT $(p<0.05)$.

In this study, mono- $\mathrm{PEG}_{2 \mathrm{k}}$-sCT was prepared, isolated by RP-HPLC and identified by MALDI-TOF from the corresponding mass spectra. The mono- $\mathrm{PEG}_{2 \mathrm{k}}-\mathrm{SCT}$ used in this study was a mixture of the N-terminus-, lysine 11-, and lysine 18 -modified $\mathrm{sCT} .{ }^{11,14)}$ We previously reported a chemical modification of $\mathrm{sCT}$ by covalent linkage with relatively higher molecular size succinimidyl carbonate monomethoxy polyethylene glycol (SC-mPEG, MW 5000 and 12000), and further isolated positional isomers of PEGylated SCTs. ${ }^{11-14)}$ The systemic clearance was unaltered for mono-PEG5K-sCT but was reduced for di-PEG $5 \mathrm{~F}-\mathrm{sCT}$ over unmodified $\mathrm{sCT}$ in rats. ${ }^{13)} \mathrm{A}$ number of other therapeutic peptides, including ribonuclease, ${ }^{15}$ tumor necrosis factor- $\alpha,{ }^{16)}$ recombinant methionase, ${ }^{17}$ recombinant human granulocyte colony-stimulat- 
ing factor, ${ }^{18)}$ and recombinant staphylokinase, ${ }^{19)}$ have been conjugated with PEG. Primary aims of the PEG modification of these peptides are to increase the metabolic stability, biological half-life, and duration of the therapeutic action. To achieve these goals, the peptides were modified with PEG of relatively large molecular weights (range $5-20 \mathrm{kDa}$ ). Knauf et $a l .{ }^{20)}$ examined the effects of PEG modification of recombinant interlukin-2 $(19.5 \mathrm{kDa})$ on changes in the pharmacokinetics as a function of the increase in the molecular mass (range $1.75-40 \mathrm{kDa}$ ). The biological half-life of interleukin2 remained unaltered with a molecular mass increase of $1.75 \mathrm{kDa}$, but was increased at molecular mass increases of $>4 \mathrm{kDa}$. In this study, sCT was covalently modified using a low molecular size succinimidyl-propionated monomethoxypolyethylene glycol (SP-mPEG, MW 2000). The elimination half-life of unmodified sCT found after nasal administration was $199 \pm 97 \mathrm{~min}$. This value is comparable to the previously reported terminal elimination half-life of unmodified $\mathrm{sCT}$ $(189 \pm 120 \mathrm{~min})$ found in rats after i.v. injection. ${ }^{13)}$ Therefore, the significant increase in the apparent terminal half-life of mono- $\mathrm{PEG}_{2 \mathrm{k}}-\mathrm{sCT}$ after nasal administration (923 $\pm 389 \mathrm{~min}$ ) may be due to a flip-flop of the absorption and elimination rate constants, i.e., the nasal absorption rate is slow relative to the elimination process. This flip-flop phenomenon may be a result of a prolonged nasal absorption of mono- $\mathrm{PEG}_{2 \mathrm{k}}-\mathrm{sCT}$ attributed by an increased stability in the nasal cavity. Our unpublished results showed that the biological activity of mono- $\mathrm{PEG}_{2 \mathrm{k}}-\mathrm{sCT}$ assessed by a cell-based cAMP assay using T47D, a human breast carcinoma cell line that endogenously expressed human CT receptors, is reduced, with the potency being $79.4 \%$ compared with unmodified SCT. Na et $a{ }^{21)}$ recently reported a dramatically increased metabolic stability of mono- $\mathrm{PEG}_{2 \mathrm{k}}-\mathrm{SCT}$ in homogenates of rat nasal mucosa. The degradation half-life was increased by 56 -fold (1386.0 min) compared with that of unmodified $\mathrm{sCT}$ (24.7 min). Our unpublished results also showed that the in vitro stability of mono- $\mathrm{PEG}_{2 \mathrm{k}}-\mathrm{sCT}$ was increased when tested in human nasal cell line RPMI 2650, with the degradation half-life being increased from $2.9 \mathrm{~min}$ for unmodified $\mathrm{sCT}$ to 20, 58, and $128 \mathrm{~min}$ for $\mathrm{Lys}^{11}{ }^{-}$, $\mathrm{Lys}^{18}{ }^{-}$, and the N-terminus modified mono- $\mathrm{PEG}_{2 \mathrm{k}}-\mathrm{sCT}$. In addition, the in vitro degradation of mono- $\mathrm{PEG}_{2 \mathrm{k}}-\mathrm{sCT}$ in rabbit nasal homogenates was also dramatically reduced, with the degradation half-life increased from $10.7 \mathrm{~min}$ for unmodified sCT to $533-1732 \mathrm{~min}$ for mono- $\mathrm{PEG}_{2 \mathrm{k}}-\mathrm{SCT}$.

\section{Summary and Conclusions}

In summary, the present study indicates that mono- $\mathrm{PEG}_{2 \mathrm{k}}{ }^{-}$
$\mathrm{sCT}$ is absorbed systemically via the intranasal route, and the extent of absorption is enhanced over unmodified sCT. The increased nasal absorption of mono- $\mathrm{PEG}_{2 \mathrm{k}}-\mathrm{sCT}$ may be due to an increased resistance to proteolytic degradation in the nasal mucosa.

Acknowledgements This study was supported by grant No. 2000-321700-00103 from the Korea Science \& Engineering Foundation.

\section{References}

1) Beveridge T., Niederer W., Nuesch E., Petrin A., Z. Gastroenterol., 10, 12-15 (1976).

2) Huwyler R., Born W., Ohnhaus E., Fischer J. A., Am. J. Physiol., 236, E15-E19 (1979).

3) Plosker G. L., McTavish D., Drugs Aging, 8, 378 - 400 (1996).

4) Sinko P. J., Smith C. L., McWhorter L. T., Stern W., Wagner E., Gillian J. P., J. Pharm. Sci., 84, 1374-1378 (1995).

5) Lee Y. H., Sinko P. J., Adv. Drug Deliver. Rev., 42, 225-238 (2000).

6) Lee W. A., Ennis R. D., Longenecker J. P., Bengtsson P., Pharm. Res., 11, 747-750 (1994).

7) Kraenzlin M. E., Seibel M. J., Trechsel U., Boerlin V., Azria M., Kraezlin C. A., Haas H. G., Calcified Tissue Int., 58, 216-220 (1996).

8) Thamsborg G., Jensen J. E. B., Kollerup G., Hauge E. M., Melsen F., Sorensen O. H., Bone, 18, 207-211 (1996).

9) Morimoto K., Miyazaki M., Kakemi M., Int. J. Pharmaceut., 113, 1 8 (1995).

10) Lang S. R., Staudenamm W., James P., Manz H. J., Kessler R., Galli B., Moser H. P., Rummelt A., Merkle H. P., Pharm. Res., 13, 16791685 (1996).

11) Lee K. C., Moon S. C., Park M. O., Lee J. T., Na D. H., Yoo S. D., Lee H. S., DeLuca P. P., Pharm. Res., 16, 813-818 (1999).

12) Lee K. C., Tak K. K., Park M. O., Lee J. T., Woo B. H., Yoo S. D., Lee H. S., DeLuca P. P., Pharm. Dev. Tech., 4, 269-275 (1999).

13) Yoo S. D., Jun H., Shin B. S., Lee H. S., Park M. O., DeLuca P. P., Lee K. C., Chem. Pharm. Bull., 48, 1921-1924 (2000).

14) Na D. H., Park M. O., Choi S. Y., Kim Y. S., Lee S. S., Yoo S. D., Lee H. S., Lee K. C., J. Chromatogr. B, 754, 259-263 (2001).

15) Láznícek M., Schiavon O., Caliceti P., Veronese F. M., Pharmacol. Res., 28, 153-161 (1993).

16) Tsunoda S., Ishikawa T., Yamamoto Y., Kamada H., Koizumi K., Matsui J., Tsutsumi Y., Hirano T., Mayumi T., J. Pharmacol. Exp. Ther, 290, 368-372 (1999).

17) Tan Y., Sun X., Xu M., An Z., Tan X., Tan X., Han Q., Miljkovic D. A., Yang M., Hoffmann R. M., Protein Expres. Purif., 12, 45-52 (1998).

18) Yamasaki M., Asano M., Okabe M., Morimoto M., Yokoo Y., J. Biochem. (Tokyo), 115, 814 -819 (1994).

19) Vanwetswinkel S., Plaisance S., Zhi-Yong Z., Vanlinthout I., Brepoels K., Lasters I., Collen D., Jespers L., Blood, 95, 936-942 (2000).

20) Knauf M. J., Bell D. P., Hirtzer P., Luo Z. P., Young J. D., Katre N. V., J. Biol. Chem., 263, 15064-15070 (1988).

21) Na D. H., Youn Y. S., Park E. J., Lee J. M., Cho O. R., Lee K. R., Lee S. D., Yoo S. D., DeLuca P. P., Lee K. C., J. Pharm. Sci., 93, 256-261 (2004). 